\title{
Ser médico no PSF: formação acadêmica, perspectivas e trabalho cotidiano
}

\section{Physicians in the Family Health Program: academic training, perspectives, and routine clinical work}

\author{
Rebeca Jesumary Gonçalves ${ }^{\mathrm{I}}$ \\ Roberta de Almeida Soares ${ }^{\mathrm{I}}$ \\ Thaís Troll ${ }^{\mathrm{I}}$ \\ Eliana Goldfarb Cyrino
}

\author{
PALAVRAS-CHAVE \\ - Educação médica \\ - Saúde da família \\ - Atenção primária à saúde \\ - Trabalho médico \\ - Equipe multidisciplinar \\ - Medicina de família e comunidade
}

\section{KEY WORDS \\ - Medical education \\ - Family health \\ - Primary health care \\ - Medical work \\ - Multidisciplinary team \\ - Family medicine}




\section{ALGUNS MARCOS HISTÓRICOS}

No início do século 20, os médicos possuíam recursos limitados para tratar seus pacientes, apoiando-se no saber e experiência pessoais, dedicando seu trabalho ao cuidado dos doentes de modo a desenvolver uma relação de proximidade e confiança. As tecnologias e as técnicas desenvolvidas na segunda metade do século 20 promoveram um período novo na história da medicina, que se tornou eficaz para um grande número de circunstâncias antes inacessíveis à cura. A atuação médica passou a se realizar de forma fragmentada, impessoal e com valorização de habilidades técnicas em detrimento da relação médico-paciente. É paradoxal, portanto, o fato de a confiança na medicina ter se ampliado durante este período, ao passo que a confiança nos médicos foi progressivamente se reduzindo, instalando-se uma crise de confiança ${ }^{1}$.

A partir da Conferência de Alma-Ata², em 1978, a Atenção Primária à Saúde (APS) ganha importância como estratégia de desenvolvimento de sistemas de saúde, implementando-se diversas propostas, como a medicina comunitária, em resposta aos altos custos do modelo de atenção médica e à inadequação da cobertura populacional desse modelo. A Organização Mundial de Saúde (OMS) passa, então, a difundir a necessidade de reforma do modelo de prestação de serviços das nações, enfatizando-se a integração dos serviços locais num sistema nacional, a participação comunitária, ações intersetoriais e maior "relação da saúde com o desenvolvimento econômico e social"3.

No Brasil, o modelo proposto pela APS teve enorme impacto na organização do sistema público de saúde. A década de 1980 significou ao Estado um momento de ressurgimento de movimentos pela democratização da sociedade, com profundos reflexos na saúde.

Na década seguinte, o Ministério da Saúde (MS) propôs a reorganização da prática assistencial, enfatizando o atendimento integral à saúde da família. O Programa de Agentes Comunitários de Saúde, implantado em 1991 com bom desempenho no Nordeste, contribuiu para que, em 1994, surgisse o Programa de Saúde da Família e na sequência, como estratégia de reorientação assistencial com caráter substitutivo às práticas convencionais ${ }^{3}$, a Estratégia de Saúde da Família (ESF), a fim de reafirmar os princípios do SUS e priorizar a $\mathrm{APS}^{4,5}$.

Shraiber ${ }^{6}$ aponta que o trabalho coletivo no PSF representa, atualmente, um grande desafio organizacional, ao passo que prenuncia uma inovação tecnológica - a medicina de dimensão mais global e ecológica de assistência, articulando-se numa atenção integral à saúde.
A ESF é considerada hoje, no contexto político-institucional brasileiro, a proposta alternativa à reorganização da atenção básica e à reorientação do modelo assistencial vigente, constituindo um enorme desafio para gestores, profissionais de saúde e toda a sociedade.

\section{A ESTRATÉGIA DE SAÚDE DA FAMÍLIA - PANORAMA E PERSPECTIVAS}

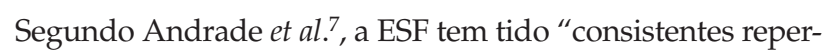
cussões positivas nos indicadores de saúde das populações por ela atendidas e na satisfação dos usuários" e com ela ocorreu aumento do número de profissionais dedicados à APS no Brasil ${ }^{8}$. Coordenadores estaduais e secretários municipais têm afirmado que a ESF vem reorganizando a APS. Todavia, há limitações à sua operacionalização devido a vários fatores: formação inadequada dos profissionais, número reduzido de médicos e falta de recursos e de compreensão dos gestores sobre a própria estratégia.

Franco e Merhy ${ }^{9}$ apontam diversas tensões presentes na potência transformadora da ESF, ao analisarem que, se a ESF não conseguir rever a forma de produzir o cuidado em saúde, dispondo-se a atuar também na direção da clínica, dando-lhe real valor com propostas ousadas como a da clínica ampliada, pode, assim como a Medicina Comunitária e os Cuidados Primários em Saúde, configurar-se na sua ação "como linha auxiliar do Modelo Médico Hegemônico" ${ }^{\prime \prime}$. Para os autores, a ESF pode persistir como um modelo no qual a ESF cuida "dos terrenos de competência da saúde coletiva" ${ }^{\prime \prime}$, e da saúde individual cuida a corporação médica.

Dessa forma, coexistem, no Brasil, equipes de saúde da família centradas no médico, assim como outras centradas no usuário, dependendo da gestão, organização e desenvolvimento local. Camargo et al..$^{10}$ constataram, em pesquisa recente, que "há uma grande diversidade na organização do processo de trabalho no PSF, diferentemente do que possa parecer, dada a regulamentação que normatiza sua organização e funcionamento".

\section{O ENSINO MÉDICO E ATENÇÃO PRIMÁRIA À SAÚDE}

Marcondes ${ }^{2}$ postula que a conferência de Alma-Ata criou um dilema ao enfatizar a importância da APS: "como mudar o enfoque do ensino médico da filosofia biocêntrica flexneriana para uma nova visão sociocêntrica do indivíduo e comunidade?".

Segundo Schraiber ${ }^{6}$, as situações assistenciais vivenciadas no Centro de Saúde quase sempre podem ser conceituadas como casos epidemiologicamente complexos. Assim, a inserção desta 
prática no aprendizado curricular médico pode contribuir tecnicamente para a formação voltada à integralidade do cuidado em todos os níveis da assistência, visando responder às demandas e necessidades de saúde da população ${ }^{11}$.

No Brasil, várias escolas médicas se propuseram a reformar seu ensino nos últimos 40 anos, tendo como perspectiva a construção de um novo paradigma, que busca responder à necessidade de mudanças nas relações entre prática médica, organização da assistência da saúde e comunicação entre médicos e pacientes $^{12}$.

A implantação das Diretrizes Curriculares Nacionais dos Cursos de Graduação em Medicina enfatiza a necessidade de formar um profissional adequado às necessidades do sistema de saúde pública ${ }^{13}$ e políticas recentes do MS, com a implantação dos projetos Promed, Aprender SUS, Pró-Saúde ${ }^{14,15}$, entre outros, que podem favorecer as referidas proposições.

Há, assim, em nosso país, um movimento de escolas médicas que vem buscando vivenciar um processo de transformação "na direção de um ensino que valorize a equidade e a qualidade da assistência e a eficiência e relevância do trabalho em saúde"16, apontando-se a importância da integração ensino-serviço.

A superação dos inúmeros obstáculos à construção de um novo modelo de exercício da medicina constitui difícil tarefa, da qual devem participar escolas médicas, governo, entidades ${ }^{17} \mathrm{e}$ sociedade.

\section{A PESQUISA}

Como sujeitos ativos na consolidação da ESF, os médicos passam por experiências novas, desafiadoras e, muitas vezes, inesperadas, que são intensificadas, sobretudo, devido à maior proximidade com a equipe, a família e a comunidade. Este trabalho objetivou investigar junto a médicos atuantes na ESF de um município a formação acadêmica, motivação para trabalhar neste campo, recursos que lhes faltam, compreensão do sistema, trabalho em equipe e vivências adquiridas na ESF.

\section{Percurso metodológico}

Trata-se de um estudo exploratório, descritivo e qualitativo centrado na ESF de Botucatu, em que foram entrevistados os médicos atuantes em 2006. Esta pesquisa foi aprovada pela Comissão de Ética da FMB e pela Secretaria de Saúde do município de Botucatu. Os participantes foram informados sobre o objetivo e finalidade do estudo e assinaram o termo de consentimento livre e esclarecido.
Etapa 1: conhecimento da gestão e organização do PSF de Botucatu

Inicialmente, apresentou-se a pesquisa aos profissionais responsáveis pela coordenação da ESF, obtendo-se informações acerca da história de implantação das Unidades de Saúde da Família (USF) a serem visitadas. Por meio de entrevista, coletaram-se dados retrospectivos sobre os desafios, dificuldades e problemas encontrados pelas equipes durante a transição UBS-ESF, a reação da população às mudanças e a modificação na prestação dos serviços de saúde, entre outros. As informações fornecidas permitiram sintetizar a situação atual da saúde no município, segundo a perspectiva dos coordenadores, e indicaram algumas características acerca de cada território. Para manter o sigilo da pesquisa, as USF foram identificadas com as letras de A a F.

Etapa 2: entrevista com médicos que atuam na ESF de Botucatu

A pesquisa foi realizada entre novembro de 2006 e março de 2007, com dez médicos que atuavam na ESF, com uma perda, tendo havido, portanto, nove entrevistas.

Os médicos foram entrevistados pelas pesquisadoras, com questões abertas. As entrevistas, com duração de 40 a 60 minutos, abordaram: o trabalho médico na ESF; a relação multidisciplinar na equipe; as vivências, dificuldades e problemas decorrentes de sua atuação profissional; a formação dos profissionais médicos; a ênfase no PSF durante sua formação acadêmica; os motivos que direcionaram sua escolha pela APS; e sua satisfação profissional. As respostas foram transcritas pelas pesquisadoras.

\section{Etapa 3: análise das entrevistas}

As entrevistas foram analisadas por meio de estatística descritiva e exploração do conteúdo. Após a leitura e compilação das respostas, selecionaram-se frases/palavras que foram repetidas com maior frequência ou enfatizadas; aquelas que se relacionaram ou que tinham aspectos em comum foram agrupadas, estabelecendo-se categorias e procedendo-se à análise e interpretação dos dados. As categorias de análise estabelecidas foram: a carência de formação em APS na escola médica e o início da carreira; o trabalho cotidiano do médico no PSF; a visita domiciliar; a relação multiprofissional na equipe; o trabalho médico no PSF - realização profissional, rotatividade e falta de perspectivas; e a compreensão da população acerca do PSF. 


\section{DESCRIÇÃO E ANÁLISE DO ESTUDO}

\section{A implantação do Programa de Saúde da Família (PSF) e as Unidades de Saúde da Família (USF)}

Botucatu, cidade do interior paulista com cerca de 120 mil habitantes, inicia, a partir da década de 1980, o processo de municipalização da saúde, com a instalação de unidades básicas de saúde municipais. De 1983 a 1996, foram instaladas sete UBS. A partir de 2003, inicia-se a implantação do Programa de Saúde da Família (PSF) em regiões periféricas da cidade, sendo algumas em caráter substitutivo e outras em novos territórios. Atualmente, cerca de $25 \%$ da população é coberta por USF.

No momento da pesquisa, cada equipe era composta por médico, enfermeiro, auxiliar de enfermagem e de quatro a oito agentes comunitários de saúde. Algumas USF realizavam atividades de saúde bucal, mas na maior parte não havia articulação com a ESF. As populações mais desprovidas de serviços de saúde, residentes em bairros distantes das UBS, foram prioritariamente beneficiadas pela ESF. Em 2006, Botucatu contava com sete USF e seis UBS, com dez equipes da ESF. O município encontrava-se em Gestão Plena da Atenção Básica.

O processo de implantação e a interação das USF com a comunidade

A análise dos dados de implantação das USF permite notar que quatro unidades (A, E, F e G) eram, anteriormente, UBS. As unidades $\mathrm{B}, \mathrm{C}$ e $\mathrm{D}$ foram implantadas em territórios que não dispunham de UBS.

De acordo com a visão dos coordenadores e médicos entrevistados, notou-se que nas unidades que eram UBS a implantação foi problemática quanto à aceitação e apoio da população e à estruturação de novas equipes. Nas unidades C e D houve boa adaptação da equipe e grande apoio popular, uma vez que em tais áreas não havia serviços de saúde. No entanto, na unidade D houve dificuldade quanto à delimitação do território. Na implantação da unidade $\mathrm{B}$, ocorreu resistência por parte dos médicos da UBS próxima ao local e da comunidade. A unidade F teve excelente aceitação, pois trouxe benefícios em relação ao serviço anterior.

Houve preocupação em esclarecer a população sobre a implantação e os objetivos do PSF. Na unidade G constata-se discrepância entre a visão dos coordenadores do programa e a dos médicos da equipe: segundo os primeiros, houve "um trabalho extenso junto à comunidade"; já para os últimos, "ainda se discute uma forma de esclarecer a população".
Quase todas as comunidades atendidas pela ESF requerem médico especialista, principalmente ginecologista e pediatra, não se sentindo confortáveis por serem atendidas por um único médico. A única exceção foi a unidade F, que considera ter havido melhoria da assistência à saúde em todos os aspectos.

Quanto à participação comunitária, verifica-se que 50\% participam efetivamente das decisões nas USF.

\section{Identificação dos sujeitos}

Foram estudados quatro médicos e cinco médicas, com idades entre 27 e 53 anos. Nenhum deles tinha se formado havia menos de um ano; cinco tinham entre 1 e 5 anos de formados; um, entre 6 e 10 anos; e três havia mais de 10 anos. A maioria trabalhava entre 1 e 5 anos, e um médico trabalhava havia mais de 10 anos no PSF.

Quanto ao tipo de contrato de trabalho, foi constatado que a inserção no PSF aconteceu para todos após processo seletivo. Na seleção não foi exigida residência médica em medicina geral e comunitária ou em medicina de família e comunidade. Todos foram contratados por meio de uma ONG, formando um quadro profissional paralelo à rede de serviço municipal. Apresentavam, em seu conjunto, um retrato preocupante da precarização da força de trabalho dedicada à ESF, como apontado em estudo ${ }^{10}$ que constatou quadro semelhante em outros municípios.

Foram citadas como residência médica: Medicina Preventiva e Social, Pediatria, Moléstias Infecciosas, Clínica Médica Geral e Homeopatia. Dois entrevistados não fizeram residência médica. Cabe ressaltar que, como a ESF é recente, a maior parte dos entrevistados se graduou antes da criação da mesma. Um entrevistado fez residência em Medicina de Família e Comunidade e três cursaram especialização em PSF. Alguns profissionais tinham mais de uma especialização.

\section{O TRABALHO MÉDICO NO PSF}

\section{A carência de formação em APS na escola médica e o início da carreira}

Merece atenção a referência unânime ao fato de o curso de graduação não ter dado destaque e capacitação aos médicos para escolher e exercer a profissão na APS. De acordo com os entrevistados, faltou enfoque para a APS na graduação que os fizesse ter uma experiência prática longitudinal na rede de saúde e obter, na formação acadêmica, uma visão abrangente do sistema básico de saúde.

[...] acredito ter faltado um enfoque maior para esta área de atuação profissional em meu curso 
de graduação. Cheguei a fazer um breve estágio no PSF - dois meses - durante o curso, no qual observei a atuação dos profissionais e funcionamento das unidades, porém ainda acho que foi pouco para ter uma visão mais abrangente da especialidade médica, não sendo isto que me fez optar por me dedicar ao PSF.

Carole et al. ${ }^{17}$ levantaram determinantes da escolha pela APS entre estudantes de Medicina, tendo encontrado como correlação direta com esta escolha: estágios obrigatórios em Medicina da Família (MF) e experiências longitudinais (com mais de um ano de duração) em APS. Entre os fatores que desestimulam a procura pela APS destacam-se a carência de conhecimento sobre o assunto e as imagens distorcidas da especialização nessa área adquiridas ao longo da graduação e fortemente influenciadas pela cultura da instituição.

Fernandes ${ }^{18}$ destaca que a prática clínica extra-hospitalar, na APS, tem "má reputação entre os médicos, na medida em que, na verdade, estes se vêem desguarnecidos de instrumentos teóricos capazes de ajudá-los a dar conta de boa parte da demanda que têm a atender".

De maneira geral, o interesse pelo PSF surgiu para os médicos por empatia pessoal com a saúde pública ou para obter um emprego para iniciar sua atuação profissional.

Escolhi o PSF porque sempre tive interesse pessoal em saúde pública e medicina da comunidade. Mesmo durante a residência em Pediatria, interessava-me pela medicina preventiva e pelo enfoque coletivo da saúde.

A importância de uma formação especializada para atuar no PSF foi unanimidade entre os médicos entrevistados. Isto pode refletir uma lacuna entre a proposta da escola médica de formar profissionais capacitados a trabalhar no setor e a realidade da assistência à saúde em nosso país. No início de seu trabalho no PSF, parte dos médicos entrevistados se considerava apta a exercer as atividades exigidas.

Entre os que não se consideravam aptos a atuar no PSF, os maiores receios se referiam à grande abrangência do trabalho (atender pessoas de todas as idades, sexo e problemas de saúde) e à necessidade de enxergar o paciente integralmente, abordando seus aspectos biopsicossociais.

Quando comecei a trabalhar no PSF, não me considerava apta a exercer a função que era imposta devido à enorme abrangência de atuação (saúde da mulher, criança, idoso, trabalhador)e à necessidade de enxergar o paciente de forma global, sem compartimentalizá-lo em pequenas subespecialidades.

Fica claro que os médicos que trabalham na produção de serviços de saúde necessitam de novas ferramentas para o trabalho na APS a partir de dinâmicas relacionais em que os diversos conhecimentos se entrelacem. "Este é um território por onde transita não apenas o mundo cognitivo, mas a solidariedade profissional está presente na boa prática de interagir saberes e fazeres e pode se mostrar eficaz na constituição de modelos assistenciais centrados no usuário" ${ }^{\prime \prime}$.

Tais constatações vão ao encontro das observações de Tron$\operatorname{con}^{11}$, para quem o sistema vigente de formação dos médicos é, ao menos em parte, responsável pelo distanciamento das práticas em saúde na comunidade.

\section{O trabalho cotidiano do médico no PSF}

O trabalho cotidiano do médico nas USF consiste em consultas clínicas, coordenação de grupos, visitas domiciliares, reuniões semanais com a equipe e campanhas educativas.

Minhas atividades cotidianas são diversificadas, abrangendo atendimento ambulatorial de adultos e crianças (puericultura), pronto-atendimento (atendimento dos eventuais), realização de pré-natal, coordenação de grupos (pré-natal, puericultura, HAS e DM) e realização de visitas domiciliares.

As consultas médicas são citadas como a principal atividade do médico, que deve atender pessoas de todas as faixas etárias e gêneros (crianças, adultos, idosos e gestantes), numa sistemática de horários que intercala pacientes agendados com a demanda eventual.

O atendimento no PSF é centralizado na figura do médico, uma vez que a idéia hospitalocêntrica ainda não acabou. Considero que a equipe de enfermagem não tem o preparo e a segurança necessários para cobrir algumas funções básicas do médico e que por isto muitas vezes fica sobrecarregada com a demanda cotidiana do PSF.

Para os médicos, o PSF, na prática, trabalha com excesso de demanda, o que prejudica a qualidade do atendimento prestado à população, com interferência na relação médico-paciente. 
O atendimento médico no PSF é realizado da melhor maneira possível dentro dos inúmeros problemas que este programa vem enfrentando [...] O excesso de consultas eventuais [...] interfere muito na qualidade dos atendimentos, que passam a ser muito direcionados e a ter um foco de pronto-atendimento e não um foco voltado para a visão do paciente como um todo.

Apesar de haver uma proposta de rotina e organização do atendimento explicitada pelos entrevistados, percebe-se que em algumas unidades o trabalho médico é definido como pronto-atendimento ou como um modelo centrado nas queixas e condutas. Isto mostra, como em outro estudo, "a persistência do modelo tradicional, da qual é evidência ainda a predominância absoluta do trabalho medicocêntrico sem interação expressiva com o restante da equipe de saúde da família"10.

As atividades de grupos de pacientes (hipertensão arterial, alcoolismo, gestantes, diabetes, cuidados em higiene, oficina de flores, atividade física, puericultura, resultados de exames) são referidas pelos médicos como um trabalho que vai ao encontro da visão educativo-preventiva da ESF. No entanto, nem todos as realizam.

Quanto às atividades em grupo, não participo delas, pois minha presença nas mesmas muitas vezes pode fazer com que sejam vistas como uma consulta em grupo, fugindo da finalidade destas atividades.

A demanda por atenção em assuntos específicos consegue ser mais abrangente com o trabalho em grupo, além de atingir grande número de pessoas ao mesmo tempo.

Constatou-se grande heterogeneidade na realização de atividades em grupo entre as unidades. Há referência a trabalhos muito pontuais, normativos e informativos, bem como à realização de oito grupos diferentes por um dos médicos entrevistados, com atividades regulares e com fundamentação teórica nos grupos operativos, ou seja, grupos que se apoiam na maior autonomia e participação dos usuários. Foi observada a existência de projetos inovadores, como o trabalho com contos de fadas no cuidado a crianças ou o denominado mulheres vitoriosas, que tem “o objetivo de que as participantes encontrem estratégias de enfrentamento da sua realidade".

\section{A visita domiciliar}

Verificou-se grande satisfação dos profissionais e usuários na realização dessa atividade, que, para eles: visa atender aos pacientes impossibilitados de irem ao Posto de Saúde (acamados, deficientes físicos), bebês com menos de uma semana de vida, pessoas idosas ou que necessitem de cuidados especiais mais próximos, pessoas após hospitalização, mães "incapazes" de cuidar corretamente de seus filhos devido a problemas de higiene ou dificuldades diversas.

As visitas domiciliares (VD) ocorrem uma vez por semana durante um período do dia. Um dos médicos não tem conseguido realizá-las, por falta de tempo: "na minha equipe, as visitas têm sido feitas pela enfermagem, que solicita a presença do médico apenas quando muito necessário".

As VD têm duração média de 10 a 30 minutos. Nesse período, são observadas as condições do domicílio (higiene, água encanada, presença de rede de esgoto, quantidade de cômodos em relação ao número de residentes) e dos moradores (idade, sexo, relacionamento entre eles, grau de parentesco, cuidadores e cuidados). Verificam-se também os problemas mais relevantes e que mais afetam a saúde de seus moradores. São efetuadas consultas médicas conforme as condições disponíveis - anamnese clínica, exame físico, coleta de exames complementares, fornecimento de medicação, realização de procedimentos como curativos, orientações gerais e educação em saúde.

[...] a importância destas visitas é reconhecer os aspectos biopsicossociais que influem no processo de saúde-doença do indivíduo e permitir uma intimidade maior no estabelecimento do vínculo médico-paciente.

Para os entrevistados, a visita domiciliar é o atendimento mais elogiado pela população e o que mais tem trazido prestígio e reconhecimento ao programa. O vínculo médico-paciente se torna mais forte nessas ocasiões, e a população passa a ter uma visão diferente e positiva da ESF. Para o médico, a realização da atividade é muito satisfatória, pois torna o exercício profissional mais próximo dos ideais de uma medicina centrada no paciente, no indivíduo e em sua comunidade.

Ronzani ${ }^{19}$ questiona "se as visitas têm sido um instrumento real de aproximação entre profissionais de saúde e as famílias no sentido de apreender-lhe o contexto e o modo de vida - ou meramente uma forma de atendimento clínico na casa do indivíduo". Na presente pesquisa, os médicos a valorizaram como uma possibilidade de conhecer e reconhecer um novo campo de relações, menos verticais, no qual se enfrenta uma situação mais diretiva, onde é necessário repensar a prática médica. 


\section{A relação multiprofissional na equipe}

Segundo os entrevistados, o trabalho em equipe contribuiu para racionalizar o atendimento ao paciente, permitindo ao médico abranger um contingente maior de pessoas, com diminuição relativa da sobrecarga. Segundo esta lógica, "as funções consideradas mais simples são delegadas a outros profissionais da saúde, a fim de permitir que algumas condutas básicas não tenham que necessariamente passar pelo médico".

Quase todos os médicos consideram ter um relacionamento excelente com a equipe, dando ênfase especial aos profissionais de enfermagem e agentes comunitários de saúde.

[...] um aspecto positivo do trabalho com equipe multidisciplinar [...] é a comunicação permanente com os agentes comunitários, que informam sobre os pacientes, suas famílias e condições da coletividade. Fazemos uma reunião semanal em que trocamos informações e discutimos o que deve ser feito para que assim consigamos ter uma relação de trabalho mais harmônica e satisfatória para todos...

Os aspectos positivos do trabalho em equipe se referem à boa comunicação, que favorece a troca de experiências em favor de uma visão integral dos pacientes, e à multidisciplinaridade, que permite incorporar diversos pontos de vista na implementação de melhores estratégias de ação nas áreas de abrangência de cada USF. Para tanto, cita-se a realização de reuniões semanais em cada unidade, momentos também utilizados para a capacitação profissional.

Esta riqueza e especificidade do trabalho em equipe na ESF, com a composição de trabalhadores de diferentes formações e escolarização, podem ser consideradas inovadoras tanto pela forma de participação de cada ator, como na complementaridade no agir, e pode ser reconhecida como um dos pilares da estratégia ${ }^{20}$.

O agente comunitário é considerado por todos um elemento fundamental à troca de informações acerca dos pacientes, possibilitando vê-los de forma integral. O agente possui uma percepção mais próxima da realidade socioeconômico-cultural que envolve cada indivíduo e sua família, permitindo individualizar a abordagem clínico-preventivo-ambiental, imprescindível ao sucesso da terapêutica instituída.

[...] um dos aspectos positivos decorrentes do trabalho com outros profissionais da área de saúde é o fato de se ver o paciente como um todo, a troca de informações, enfoques diferentes, tanto psíquico como social. Os agentes de saúde con- tribuem muito, trazendo a realidade em que os pacientes estão inseridos, mostrando seus problemas além da doença que, em última instância, acabam gerando a doença [...]

Já entre os aspectos negativos referentes à relação interprofissional, aponta-se a alta rotatividade dos profissionais em cada unidade - especialmente auxiliares de enfermagem -, faltando uma figura de referência para ocupar estes cargos em alguns locais. Em algumas unidades, surge como problema o fato de a equipe ter um número muito grande de agentes comunitários, dificultando o contato e a comunicação do médico com estes profissionais. Em algumas unidades, citou-se a dificuldade de conseguir pessoas habilitadas para exercer tal função.

A falta de capacitação de alguns membros da equipe, que se adaptam a funções para as quais não têm formação, é citada como um fator crítico na relação da equipe, tornando muito difícil a imposição de limites de atuação de cada profissional. Apesar da divisão de tarefas, os entrevistados afirmam que alguns pacientes não aceitam ser atendidos por profissionais não médicos, o que gera constrangimento e desconforto nas equipes. A liderança da equipe tem acarretado muito desgaste e sobrecarga aos médicos do ponto de vista laboral e emocional, como relatam os entrevistados.

[...] os aspectos negativos decorrentes do trabalho em equipe para mim são: o fato de alguns profissionais não gostarem de muitas cobranças; e o fato de a responsabilidade pela liderança da equipe acabar recaindo sobre o médico, o que acarreta certo desgaste e sobrecarga.

Quanto à atuação dos profissionais que trabalham nas equipes, estes precisam se identificar "com uma proposta de trabalho que, muitas vezes, demanda criatividade, iniciativa e vocação para trabalhos comunitários e em grupo. Portanto, o PSF exige uma mudança estrutural na formação e nas práticas dos profissionais de saúde"19, pois os profissionais se deparam com uma prática nova, diferente das experiências anteriores e na qual há uma "lógica operativa diferente da que os profissionais de saúde estavam, até então, habituados"19.

Também foram observados conflitos na divisão de trabalho e no poder na equipe.

\section{O trabalho médico no PSF: realização profissional, rotatividade e falta de perspectivas}

Os médicos se sentem parcialmente realizados em trabalhar no PSF. Apontam como causas de insatisfação o excesso de con- 
tingente e a falta de respaldo tanto do setor secundário, para encaminhamento dos casos mais graves, como das instâncias governamentais, que burocratizam o atendimento e inflam o programa, destinando poucos profissionais para trabalhar numa área de abrangência muito grande.

[...] não estou plenamente satisfeita no PSF. O serviço tem melhorado bastante, mas ainda faltam muitas coisas para que se faça um trabalho mais humanizado [...] Atender com efetiva qualidade e humanização em apenas dez minutos é um desafio que prejudica a satisfação profissional do médico.

Alguns entrevistados se consideraram preparados para atuar no PSF, tanto pela formação anterior, após a graduação, como por se reconhecerem e se identificarem com o trabalho médico na ESF. Neste sentido, sentem-se gratificados por poderem tratar o paciente na perspectiva da integralidade do cuidado. A maior aproximação do PSF pode ser "facilitada quando os médicos são seduzidos pelos seus princípios e estes vêm ao encontro do desejo de ruptura com a racionalidade médica tradicional" ${ }^{21}$. Porém, o trabalho cotidiano aponta fragilidades "de diferentes ordens infraestrutura, condições de trabalho, perfil sócio sanitário das áreas atendidas, entre outras - que repercutem claramente na motivação dos profissionais e, certamente, limitam o alcance dos objetivos pretendidos pelo PSF" ${ }^{21}$.

Sinto-me realizado em trabalhar no PSF, foi onde me encontrei na medicina. O que me agrada é o fato de se dividir as responsabilidades com a equipe, pois "saúde não é só do médico", e acho que esta estratégia de atendimento ajuda o paciente a desenvolver autonomia.

A realização profissional parcial, somada ao limitado reconhecimento do médico por parte da população e de outros médicos, tem desestimulado a permanência dos profissionais no programa, gerando grande rotatividade e dificultando a criação de um vínculo adequado e duradouro com a população. Existem ainda a questão salarial e as condições desfavoráveis de trabalho. Durante o período deste estudo, dois dos nove médicos entrevistados deixaram de atuar no PSF de Botucatu. No final desta pesquisa, mais dois médicos haviam deixado a atividade, comprovando a alta rotatividade de médicos no PSF.

A população é a mais prejudicada com esta grande rotatividade, uma vez que, sem a criação de um vínculo efetivo, as pes- soas deixam de fazer um acompanhamento regular e se perpetua a cultura dos atendimentos eventuais.

A atividade diversificada do profissional requer uma disponibilidade de dedicação em períodos além dos estabelecidos pelos contratos de trabalho, embora não haja pagamento adicional. Os médicos apontam que a forma como estão sendo realizados os contratos trabalhistas, ligados a instituições não públicas, prejudica muito o trabalho e a perspectiva da proposta.

Pesquisa recente sobre a trajetória de médicos no PSF apontou a "instabilidade do vínculo trabalhista e, consequentemente, a insegurança que isto provoca no profissional" como um dos principais "responsáveis pela alta rotatividade dos profissionais que atuam nas equipes do PSF" ${ }^{21}$.

Outra limitação apontada é a falta de apoio matricial de profissionais (psicólogos, fisioterapeutas, dentistas e fonoaudiólogos) à equipe, o que prejudica o cuidado à população.

Como aspectos falhos no PSF temos os obstáculos encontrados para a realização de atividades de prevenção e educação em saúde: a falta de tempo para poder preparar tais assuntos para a comunidade, associada à carência de material didático, dificulta essas atividades; a falta de horários livres para coordenar grupos, aliada a excessiva demanda por eles; a pouca valorização do trabalho médico - o salário é incompatível com o elevado grau de responsabilidade, comprometimento e necessidade de dedicação do profissional; o que explica, em parte, por que poucos profissionais competentes e preparados se interessam pelo trabalho no PSF; excessiva demanda e desgaste profissional [...].

Os entrevistados apontam a dificuldade de encaminhamentos a especialidades médicas, devido à escassez do setor secundário público municipal, apesar de estar presente na cidade o $\mathrm{HC}$ da Unesp, que possui serviços especializados estruturados e boa incorporação tecnológica. Os entrevistados referem que pacientes que necessitam de atendimento especializado aguardam longo período para conseguir a consulta. Assim, há um descrédito da população, identificando a inadequação do modelo.

Já tive algumas decepções durante meu trabalho no PSF, sendo a maior delas referente ao sistema de saúde como um todo. Tive um paciente em que suspeitei do diagnóstico de câncer de intestino, mas, devido à demora no encaminhamento, ele não conseguiu uma consulta com o especialista na 
rede pública de saúde e precisou fazer uma consulta particular para ter seu diagnóstico confirmado (quatro meses após eu ter feito a suspeita), quando o câncer já havia avançado muito em seu estadiamento. Isso me faz desacreditar no sistema de saúde público do País.

Apesar de alguns médicos não conseguirem formular sugestões para melhorar o PSF que vem sendo realizado, o que a maioria deles sustenta é a necessidade de repensar a quantidade de pacientes a ser atendida por cada equipe - mediante redistribuição das áreas de abrangência ou aumento do número de equipes e mesmo maior integração no trabalho em equipe.

Gostaria de estar muito mais engajada e empenhada nos programas dentro da unidade. Porém, por problemas organizacionais e gerenciais, consigo colocar pouca coisa em prática e meus projetos acabam ficando esquecidos por longos períodos, sendo que muitos deles nem mesmo chegam a ser discutidos.

Outras questões abordadas se referem à necessidade de capacitação profissional e educação permanente para toda a equipe do PSF, reestruturação do setor secundário no município para acolher os encaminhamentos e maior atenção das escolas médicas ao ensino na APS.

É fundamental que haja maior e melhor qualificação dos profissionais que queiram trabalhar nesta área, dando uma atenção especial ao ensino de graduação, que deveria priorizar o atendimento médico básico, já que é com isto que a maioria dos alunos terá maior contato durante toda sua vida, e para que assim muitos deles possam optar de forma consciente pela área da medicina que querem seguir, conhecendo todas sem preconceito.

Para Camargo et al. ${ }^{10}$, a educação permanente está longe da realidade para a maior parte dos municípios. "Percebe-se que um dos grandes nós górdios no caminho da implantação do PSF de forma abrangente é a gestão de recursos humanos em sentido amplo".

Ao olharem para o futuro, os médicos apresentam uma visão pessimista da ESF. Acreditam no potencial da ESF e elogiam sua fundamentação, porém são críticos ao falarem da importância de uma atenção maior dos órgãos governamentais competentes na elaboração de políticas públicas mais compatíveis com a realidade do País.

[...] a ideologia e o projeto do PSF são maravilhosos do ponto de vista teórico, mas não se tornaram possíveis na prática, uma vez que o governo não tem investido a quantidade suficiente de verbas, nem ampliado o número de equipes. Deste modo, o médico e demais profissionais da equipe ficam [...] frustrados por não poder fornecer a qualidade que gostariam no atendimento aos pacientes. Acredito que o PSF não melhorará a situação de saúde no País, a menos que a vontade política organize, amplie e dê as condições mínimas necessárias ao funcionamento adequado e digno do projeto.

“Neste movimento, o médico passa a questionar os alicerces ideológicos que nortearam historicamente sua prática e se coloca perante a possibilidade de ressignificação da própria identidade profissional" $^{21}$. No entanto, ainda se colocam como vítimas do sistema.

\section{A compreensão da população acerca do PSF}

Segundo os médicos, a população ainda está num processo de adaptação à ESF, compreendendo aos poucos sua lógica. Alguns pacientes solicitam a presença do ginecologista e do pediatra nas unidades. Uma constante reclamação se refere à demora no agendamento das consultas, gerando uma busca frequente pelo atendimento eventual.

A população gosta do PSF e considera-o bom, mas ainda solicita outros médicos especialistas e reclama em função do tempo de espera e da demora para agendar novas consultas e retornos. As pacientes gestantes e as mães ainda preferem que haja um atendimento com ginecologista e pediatra na unidade.

Cada USF tem sua história, sendo possível identificar unidades com maior ou menor vínculo com a população e com grande frustração por não conseguirem responder às demandas da população.

\section{CONSIDERAÇÕES SOBRE O TRABALHO MÉDICO NA ESF}

O SUS representa um enorme avanço para promover as transformações rumo à construção de um novo modelo de atenção à sa- 
úde. A complexidade para mudar as bases que sustentam o modelo médico assistencial predominante no País vem sendo descrita nas ultimas décadas e retrata a necessidade de compreender os determinantes da hegemonia do modelo sanitário.

A ESF é hoje, no Brasil, a estratégia construída pelo MS para enfrentar a crise do setor saúde, buscando recompor a prática da APS. Tem a expectativa de reorganizar a prática assistencial com novas bases e critérios, mas apresenta grandes desafios e impasses para romper com o modelo médico hegemônico.

Neste trabalho, foi possível conhecer o cotidiano de médicos que atuam na ESF de um município do interior paulista, observando-se, na descrição do trabalho ali realizado, processos sociais contemporâneos mais amplos, como a crise da medicina liberal e do modelo hospitalocêntrico; a persistência de uma formação acadêmica fragmentada e basicamente hospitalar e a falta de educação permanente voltada ao reconhecimento dos problemas da realidade local; a tendência à precarização do trabalho; a dificuldade e o desafio no trabalho em equipe no campo da saúde, que inclui diferentes sujeitos com distintas formações e grande vontade de se inserir em um novo modelo de atenção à saúde, que tem valorizado a responsabilidade, o cuidado e a integralidade. São questões presentes em estudos recentes ${ }^{10,19}$ e que aqui se revelam na análise do contexto de implementação da estratégia em um campo de possibilidades e de limites para a consolidação do novo modelo de reordenamento da atenção básica ${ }^{10}$.

Chama a atenção o fato de nenhum dos entrevistados relatar ênfase na APS durante a graduação, nem receber incentivos e informações necessários para optar por este campo de trabalho. Como parte dos entrevistados era formada nos cinco últimos anos, percebe-se que, apesar dos esforços presentes, as escolas médicas persistem em não potencializar a prática médica extra-hospitalar, que necessita, obrigatoriamente, da interação entre o conhecimento "médico sobre os processos de adoecimento e o conhecimento do paciente sobre sua vida, sem os quais não há possibilidade de desenvolvimento de um diagnóstico e de uma ação terapêutica consistentes"18.

Para atuar na ESF e realizar um atendimento médico tecnicamente consistente, é necessária uma formação que amplie o campo de percepção clínica, "sob o risco de se desenvolver uma atuação profissional superficial, ineficiente e de baixa resolutividade, dominada pela monotonia e repetitividade oriundas da pobreza fisiopatológica dos casos e da estreiteza do olhar médi$\mathrm{Co}^{\prime \prime 18}$. Constata-se ainda uma tendência muito forte em se considerar o trabalho na APS como algo de menor valor e prestígio no meio acadêmico quando comparado ao trabalho de outras especialidades médicas.
Todos referem excesso de trabalho e responsabilidades e a necessidade de organização dos outros níveis de assistência no município, descrevendo especificamente a ausência de uma rede regionalizada de referência e contrarreferência de serviços assistenciais. Assim, percebem-se os limites do trabalho na APS que, por si só, mesmo realizando um trabalho de qualidade sob uma ótica ampliada do cuidado, não altera substantivamente a lógica organizativa dos serviços, em que predomina a assistência a doenças em suas demandas espontâneas, centradas no apoio diagnóstico, equipamentos e medicamentos.

Apesar das inúmeras dificuldades, os médicos identificam que a população tem reconhecido o trabalho do PSF e tem sido possível desenvolver uma relação médico-paciente adequada, valorizando-se o trabalho em grupo de diversas atividades.

A receptividade dos médicos à entrevista revela uma postura responsável, aberta e crítica, com muita vontade de participar ativamente como sujeitos da construção da ESF.

\section{AGRADECIMENTOS}

Agradecemos aos médicos do PSF de Botucatu pela disponibilidade e interesse na construção deste estudo.

\section{REFERÊNCIAS}

1. Schraiber LB, Mendes-Gonçalves R, Nemes MIB. Saúde do adulto: programas e ações na unidade básica. São Paulo: Hucitec; 1996.

2. Marcondes E. A conferência de Alma-Ata e as Ações Básicas de Saúde. In: Issler H, Leone C, Marcondes C. Pediatria na Atenção Primária. São Paulo: Savier; 2002.

3. Conill EM. Ensaio histórico-conceitual sobre a Atenção Primária à Saúde: desafios para a organização de serviços básicos e da Estratégia de Saúde da Família em centros urbanos no Brasil. Cad. Saúde Pública. 2008;24(Supl.):7-27.

4. Viana ALD; Poz MRD. A reforma do Sistema de Saúde no Brasil e o Programa de Saúde da Família. Rev. Saúde Coletiva. 1998;8:11-48.

5. Manfredini M. Saúde bucal coletiva: metodologia do trabalho e Práticas. [S.1.]: Ed. Santos; 2005.

6. Schraiber LB. O Centro de Saúde. In: Issler H, Leone C, Marcondes C. Pediatria na Atenção Primária. São Paulo: Savier; 2002.

7. Andrade LOM, Barreto ICHC, Fonseca CD. A Estratégia de Saúde da Família. In: Duncan B, Schmidt MI, Giugliani ERJ. Medicina Ambulatorial. $3^{\underline{a}}$ ed. Porto Alegre: Artmed; 2004. p. 88-100. 
8. Conill EM. Políticas de Atenção Primária e Reformas Sanitárias: discutindo a avaliação a partir da análise do Programa de Saúde da Família em Florianópolis, Santa Catarina, Brasil, 1994-2000. Cad. Saúde Pública. 2002;18(Supl.):191-202.

9. Franco T, Merhy E. PSF: contradições e novos desafios. [documento na internet]. Conferência Nacional de Saúde On-Line. Campinas, mar. 1999. [acesso em 27 out. 2008]. http://www.datasus.gov.br/cns/temas/tribuna/PsfTito.htm

10. Camargo Jr. KR. et al. Avaliação da atenção básica pela ótica político-institucional e da organização da atenção com ênfase na integralidade. Cad Saúde Pública. 24 (Suplemento1): 58-68, 2008.

11. Troncon LEA. Ensino clínico na comunidade. Medicina, Ribeirão Preto, 32: 335-344, jul./set. 1999.

12. Cabral Filho WR; Ribeiro VMB. A escolha precoce da especialidade pelo estudante de medicina: um desafio para a educação médica. Rev Bras Educ. Méd. v. 28 (2): 133-144, 2004.

13. Brasil. Ministério da Educação. Conselho Nacional de Educação. Câmara de Educação Superior. Resolução CNE/CES n. 4, de 7 de novembro de 2001: Institui diretrizes curriculares nacionais do curso de graduação em medicina. Brasília, 2001.

14. Brasil. Ministério da Saúde. Secretaria de Políticas da Saúde. Coordenação Geral da Política de Recursos Humanos. O Programa de Incentivo às Mudanças Curriculares para as Escolas Médicas. PROMED. Brasília, 2002.

15. Brasil. Ministério da Saúde. Ministério da Educação. Programa Nacional de Reorientação da Formação Profissional em Saúde - PRÓ-SAÚDE. Brasília: Ministério da Saúde; 2005.

16. Cyrino EG, Rizzato ABP. Contribuição à mudança curricular na graduação da Faculdade de Medicina de Botucatu. Rev Bras Saúde Mater Infantil. 2004;4(1):59-69.

17. Carole JB, Meurer LN, Maldonado G. Determinants of primary care specialty choice: a non-estatistical meta-analysis of the literature. Acad Méd. 1995;70(7):620-41.
18. Fernandes JCL. A quem interessa a relação médico-paciente? Cad Saúde Pública. 1993;9(1):21-27.

19. Ronzani TM, Silva CM. Brazil's Family Health Program according to healthcare practitioners, managers and users. [artigo na internet]. Ciên Saúde Colet. 2008;13(1):23-34. [acesso 02 2008]. doi:S1413-81232008000100007.

20. Matumoto S, Fortuna CM, Mishima SM, Pereira MJB, Domingos NAM. Supervisão de equipes no Programa de Saúde da Família: reflexões acerca do desafio da produção de cuidados. Interface Comun Saúde Educ. 2004/2005;9(16)9-24.

21. Rocha, AARM, Trad, LAB. A trajetória profissional de cinco médicos do Programa Saúde da Família: os desafios de construção de uma nova prática. Interface Comum Saúde Educ. 2005;9(17):303-16.

Apoio: Esta pesquisa obteve apoio do Pibic - CNPQ/FMB/Unesp - Processo 2006/2007 e da Reitoria Unesp 2008 - Bolsa de iniciação científica.

\section{CONTRIBUIÇÃO DOS AUTORES}

Todas as autoras participaram e contribuíram na concepção e no desenho da pesquisar realizada e na análise e interpretação dos resultados, assim como da discussão dos mesmos. Todas participaram da redação final do texto e concordam com a versão final para publicação

\section{CONFLITO DE INTERESSES}

Declarou não haver

\section{ENDEREÇO PARA CORRESPONDÊNCIA}

\author{
Eliana Goldfarb Cyrino \\ Departamento de Saúde Pública \\ Faculdade de Medicina de Botucatu - Unesp \\ Rubião Junior, s/n Botucatu \\ CEP.: 18600-000 SP \\ E-mail: ecyrino@fmb.unesp.br
}

